\title{
Strengthening the composite protective shield of light- weight ship against ballistic impacts: Analytical and Experimental
}

\section{Abstract}

Light and medium protection for small naval vessels guarantees their high performance and safety during the guard duties. In this study, a protective shield fabricated from Dyneema HB25 fibers has been utilized as an add-on layer on the coast guard boat hull. Finite element analyses have been conducted using Chocron's model. Two standards of gun-fire were employed and various thicknesses of the composite layers were examined by ballistic impacts. Afterward, numerical simulations results compared with experiments and revealed a good consistency. Finally, some graphs have been presented to help designers for choosing more convenient shield based on protection and weight characteristics after judgment of vessel requirements.

\section{Keywords}

coast guard boat, ballistic impact, Dyneema, polymer composite, numerical simulation, FEM
I. Jalili, Z. H. Nouri*,

A. Z. Aabady, K. Akbari V.

Mechanical Group, Marine Science Noshahr

University, Noshahr, Iran

Received 26 Sep 2012

In revised form 01 Mar 2013

*Author email: zorareh@gmail.com

\section{INTRODUCTION}

From the early $20^{\text {th }}$ century, armor materials have been developed generally of high hardness steel. However, in the last few decades the importance of lightweight protection has led to invention of alternative materials [1]. Due to their high strength, low density, extreme toughness and their outstanding performance against small and medium caliber projectiles, polymers have become widely used in armors and the subject of many researches. In particular, when the weight is a design concept, protection or body armor for light weight vehicles, specially naval vessel becomes critical [2].

The prominence of manufacturing coast guard boat hull with Dyneema composite is the feasibility of shaping in regards to other materials such as ceramic composites. The other factor that has to be considered in building hull is its areal weight. Dyneema composite are lighter than common high strength fabric such as Kevlar and far less than ceramics.

Weight reduction for current and future military systems is crucial in fast deployment of marine circumstances. In the near future, ultra-light weapon platforms will be promising for conquering the 
battlefields. Some military strategies set the trend for extensive weight reduction in future Army platforms that require novel technology. Therefore, New materials and design concepts are required to meet these challenges [3]. In this regard, various experimental and theoretical investigations have been carried out on the ballistic impact of composite protections, so far [4-11].

The object of the present study is to simulate ballistic impact and improving the strength of the coast guard boat hull while reducing its total weight, by employing shaped Dyneema composite layout as an outer hull layer. In order to assess the performance of this protective shield against ballistic threats, finite element method (FEM) and empirical investigation have been employed. FEM analysis has been carried out by ABAQUS/Explicit one of robust finite element analysis software. To obtain realistic results from this analysis, the mechanical and physical properties of Dyneema fibers in high strain rates fed into the software as initial data.

Furthermore, experimental investigations were also carried out on prepared sample of Dyneema composite of various thickness with different projectiles. Next, the experimental results were analogized with simulation predictions. Finally, some thickness selection assistant curves for building coast guard boat shield resistant to projectiles have been presented to facilitate designing based on vessel functionality and risk assessment.

\section{ANALYTICAL METHOD}

The highly complicated problems of a projectile impacting polymer/composite layers has already been studied thoroughly by different researchers such as; Duan [12], Karahan [13], Chocron [14] and Bürger [15]. It is not the objective of this paper to improve their impact models but simply to use them, and to build a composite one. In the following the reader can find the most important results obtained by the authors and how they have been applied to this problem.

A simple analytical model of impact onto a fabric has already been published by Chocron et. al [16] including the basis of the model. The model has been checked and a good agreement was obtained compared with analytical and numerical ones [17]. According to this model, the kinetic energy of the projectile is transferred to the plate through two mechanisms: straining and breaking of the yarns, and delamination.

In order to analyze the first mechanism, the equation of motion of the projectile is driven:

$$
M_{p} \frac{d \bar{V}}{d t}=2 \bar{F}
$$

In which, $M_{p}$ is the projectile mass, $V$ is its velocity and $F$ is the force being exerted from the composite yarns on the projectile (Fig. 1). 


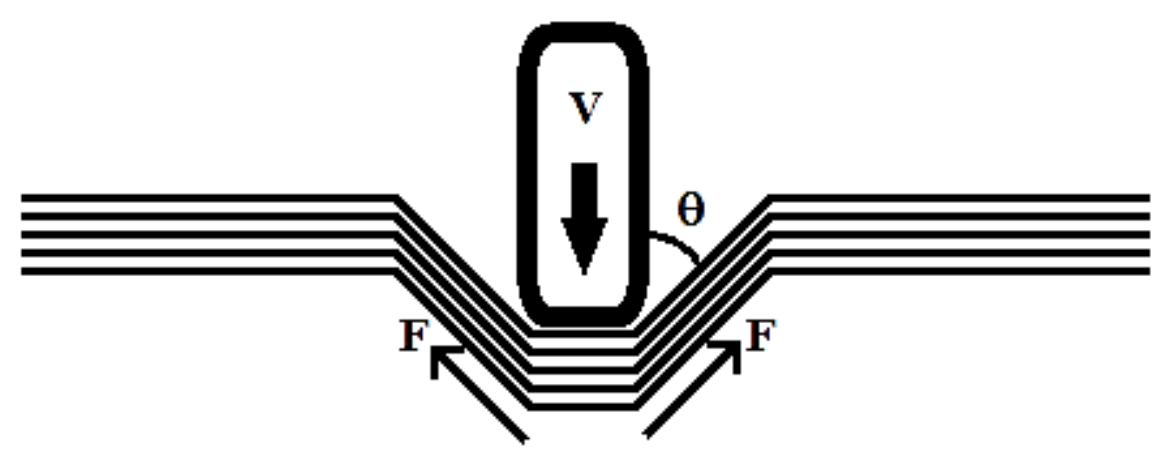

Figure 1 Configuration of impact forces on the composite layers.

The force that yarns exert on the projectile estimated earlier by Chocron [17]:

$$
F=E \varepsilon S n_{1} n_{y}
$$

Where $F$ is the component of the force in the direction of motion, $E$ the Young modulus of the yarns, $\varepsilon$ the strain of the fabric under the projectile, $n y$ the number of yarns in direct contact with the projectile, $S$ the section of the yarn and $n_{1}$ is the number of layers of the fabric.

Moreover, the analytical solution for constant velocity impact derived by Smith [18]. When a point projectile impacts a linear elastic yarn, the velocity of the projectile $\left(\dot{u}_{0}\right)$ and the strain $(\varepsilon)$ are related by Eq. 1:

$$
\dot{u}_{0}=c_{y} \sqrt{2 \varepsilon \sqrt{\varepsilon(1+\varepsilon)}-\varepsilon^{2}}
$$

This equation also validated for non-constant velocity impact [16]. In Eq. 3, $c_{y}$ is the longitudinal speed of sound in the yarn. Smith also calculated the angle between the line of impact and the yarn (Fig. 1):

$$
\sin \theta=\frac{\sqrt{2 \varepsilon \sqrt{\varepsilon(1+\varepsilon)}-\varepsilon^{2}}}{\sqrt{\varepsilon(1+\varepsilon)}}
$$

Smith's model gives the strain and the angle $\theta$. All the yarns are assumed to have the same strain through the textile thickness to keep the analytical model simple enough; weave and crimp are not considered.

Defining failure criteria is the second part of the analysis. Prosser [19] proposed that the absorbed energy by the fabric when full perforation occurs should be unchanging regardless of the impact velocity. This proposition together with the energy equation states that the energy lost by the projectile during the impact has to be equal to the energy absorbed by the fabric: 


$$
\frac{1}{2} M_{p}\left(V_{s}^{2}-V_{r}^{2}\right)=\frac{1}{2} n_{1} n_{y} S E c_{y} \int_{0}^{t} \varepsilon^{2} d t
$$

Another way to write Eq. 5 is:

$$
\frac{M_{p} V_{50}^{2}}{n_{1} n_{y} S E c_{y}}=\int_{0}^{t_{f}} \varepsilon^{2} d t \equiv R
$$

Where $t_{f}$ is the time of failure, $\mathrm{R}$ is called failure constant and it is only dependent on the configuration, but not on the impact velocity. Finally, $V_{50}$ is the ballistic limit. With one single test the designer can calculate $\mathrm{R}$, by forcing the analytical and experimental residual velocity to be equal, and then use it to analyze all impact velocities. A more general failure model is easily derived: as $\mathrm{R}$ depends on the configuration, let $R_{i}$ be the failure constant for the target configuration $i$ and $R_{0}$ be the one for a reference target configuration, from Eq. 6 it follows:

$$
\frac{\left(M_{p}\right)_{i} n_{y o}\left(n_{1}\right)_{0}\left(V_{50}^{2}\right)_{i}}{\left(M_{p}\right)_{0} n_{y i}\left(n_{1}\right)_{i}\left(V_{50}^{2}\right)_{0}} R_{0}=R_{i}
$$

This formula can be very useful if some empirical value for $V_{50}$ is assumed or found experimentally. For instance, Van Gorp [20] found that Dyneema (or Spectra) armors verify for fragment simulating projectiles. The ballistic limit of Dyneema armors can be explicitly written with a very simple expression:

$$
V_{50}=232 \delta^{0.5} W^{-1 / 6}
$$

Where $\delta$ is the areal density of the armour in $\mathrm{kg} / \mathrm{m}^{2}$ and $W$ is the mass in grams of the projectile. This equation allows the calculation of the failure constant for each configuration with the Eq. 7 and then the problem of the impact can be fully solved.

It is assumed that the failure happens just under the maximum strain or strength criteria. According to Eq. 3, higher values of impact velocity coincide with the greater magnitudes of the strain which is occurred at the beginning of the impact process (i.e. when the velocity of projectile is the maximum).

\section{FINITE ELEMENT ANALYSIS}

A 3D FEA model is created using ABAQUS/Explicit to simulate the impact. The impact system is an axisymmetric with respect to $z$ axis. Fig. 2 shows the initial geometry of an impact configuration; a rigid projectile transversely impacts onto the center of a patch of plain-woven Dyneema fabric. 4-node bilinear axisymmetric quadrilateral elements (CAX4R) assigned for Dyneema fabric, and an analytical rigid characteristic for bullet. The dimensions of fabric and bullet in analysis are identical to experimental geometry.

Latin American Journal of Solids and Structures 10(2013) $1211-1223$ 


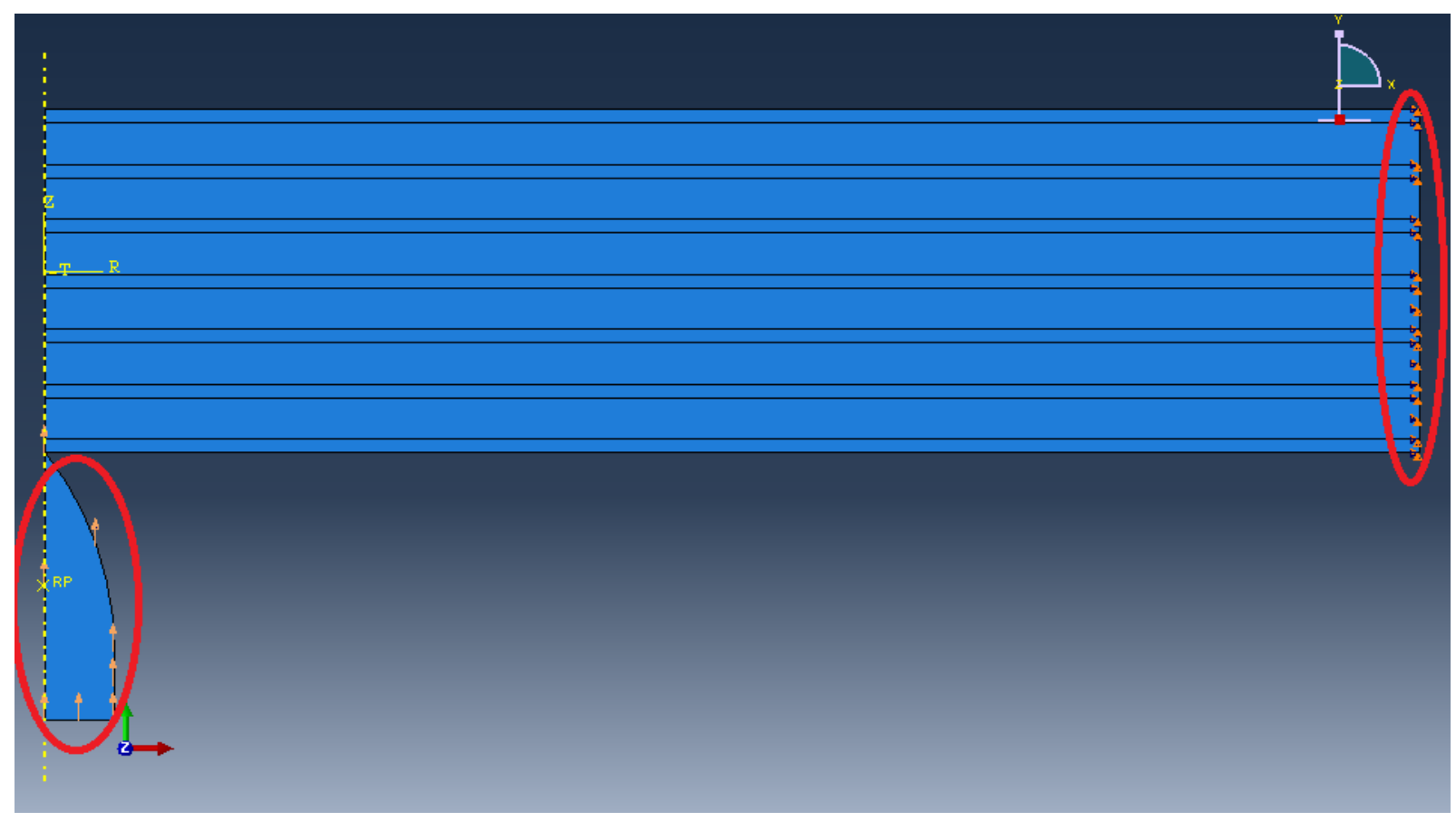

Figure 2 Boundary and initial conditions of FE model: Initial velocity (left), UX=UY=0 (Right)

The material properties of the Dyneema yarn have been given in the Table 1. Each Dyneema layer has stacked with 90 degree rotation in respect to the epoxy layer. Fig. 3 shows composite layers configuration after mesh sensitivity analysis (thinner layer is Dyneema and thicker one is epoxy).

Table 1

\begin{tabular}{|l|l|}
\hline \multicolumn{2}{|l|}{ Mechanical properties of a single composite ply (Dyneema ${ }^{\circledR}$ HB25) [15]. } \\
\hline$\rho$ & $970 \mathrm{~kg} / \mathrm{m}^{3}$ \\
\hline $\mathbf{E}_{\mathbf{1}}$ (in-plane) & $297 \mathrm{GPa}$ \\
\hline $\mathbf{E}_{\mathbf{2}}$ (out-of plane) & $10.8 \mathrm{GPa}$ \\
\hline $\mathbf{G}_{\mathbf{1 2}}$ & $5.0 \mathrm{GPa}$ \\
\hline$U_{\mathbf{1 2}}$ & 0.3 \\
\hline
\end{tabular}




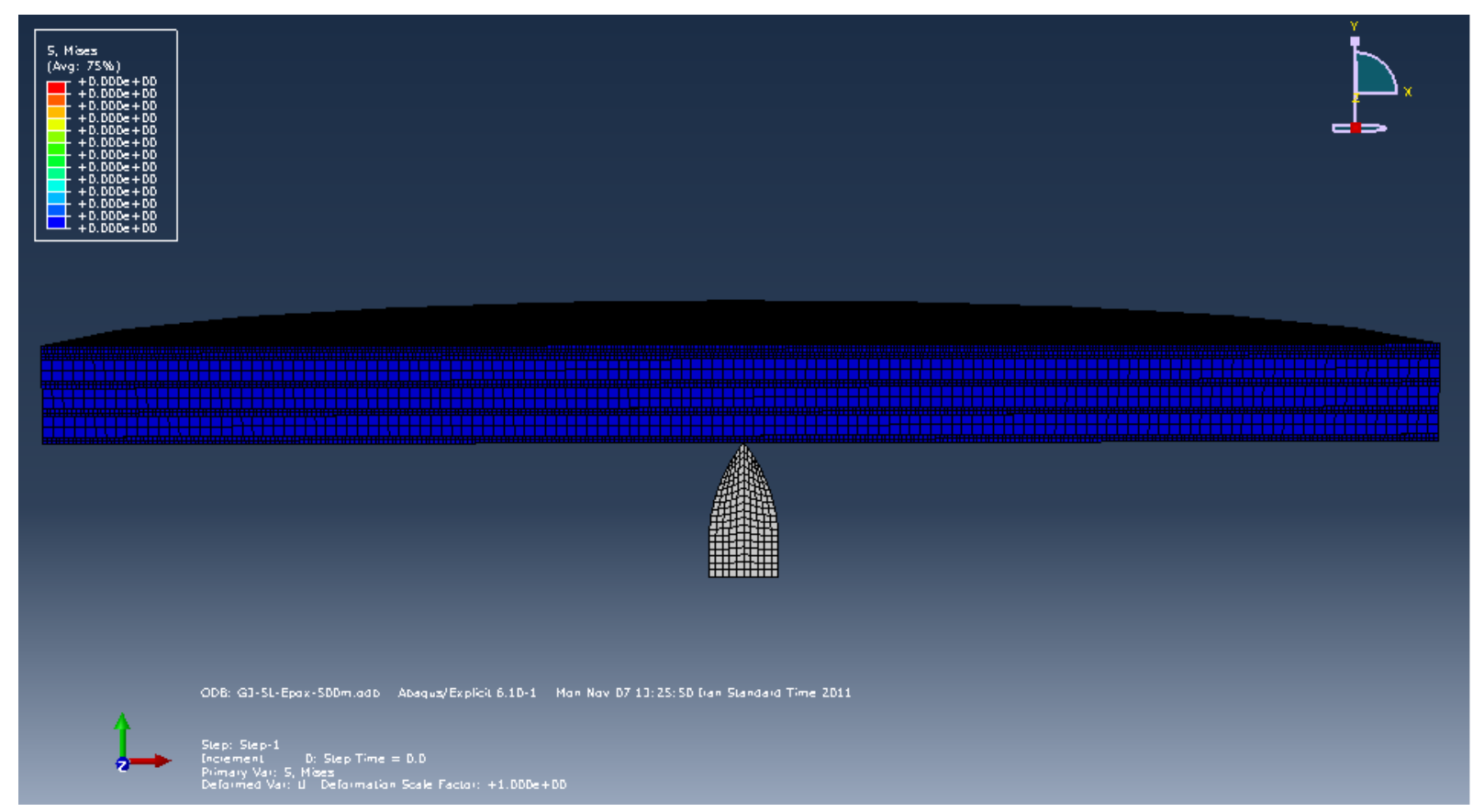

Figure 3 Configuration of layers (thinner layer is Dyneema and thicker one is epoxy).

To explore the effect of impact velocity on the fabric ballistic performance, two cases are modeled by two projectiles of $7.62 \times 51 \mathrm{~mm}$ NATO AP and $7.62 \times 39 \mathrm{~mm}$ where the impact velocity is 780 $\mathrm{m} / \mathrm{s}$ and $690 \mathrm{~m} / \mathrm{s}$, respectively and four different types of fabric, composed of various numbers of Dyneema layers; i.e. 15, 21, 27, 30 (layers), respectively.

\section{EXPERIMENTAL PROCEDURE}

Experiments were carried out in this work according to Table 2 condition and Fig. 4 arrangement. The composite panels were fabricated by stacking Dyneema layers with $250 \mathrm{MPa}$ pressure in temperature of $125^{\circ} \mathrm{C}$ degree for 15 min using epoxy layers. Eight shooting tests were carried out according to NIJ 0101.03 standard. Two types of projectiles used in these tests are $7.62 \times 51 \mathrm{~mm}$ NATO AP and $7.62 \times 39 \mathrm{~mm}$. The shooting results are presented as complete penetration $(\mathrm{CP})$, partial penetration (PP) or no penetration (NP). After shootings, the depth and diameter of trauma formed on the backing material were measured (table 4).

Table 2

\begin{tabular}{|c|c|}
\hline \multicolumn{2}{|c|}{ Test Condition According to NIJ 0101.06} \\
\hline Test Temperature & $21^{\circ} \mathrm{C} \pm 2.9^{\circ} \mathrm{C}$ \\
\hline Humidity & $50 \% \pm 20 \%$ \\
\hline Angle of Bullet Encounter & $50 \mathrm{deg}$ \\
\hline Test Endurance & 10 Days \\
\hline Backing Material Dimension & $140 \times 610 \times 610 \mathrm{~mm}^{3}$ \\
\hline
\end{tabular}

Latin American Journal of Solids and Structures 10(2013) $1211-1223$ 


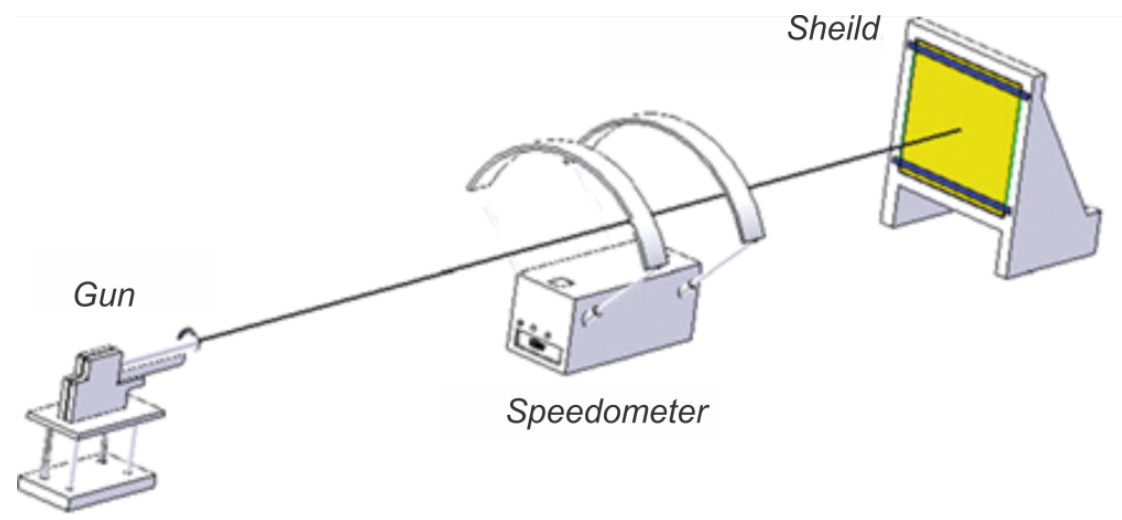

Figure 4 Test arrangement

\section{RESULTS AND DISCUSSION}

The finite element model of the projectile and armor was shown in Fig. 3. Due to the axi-symmetric nature of the problem, only half of the projectile-armor system is modeled. Eight different experiments, with two types of projectile and four different thicknesses, were analyzed by FEM simulation and analytical model using the proposed models. The residual velocities of projectiles after impact on composite plates are presented in Table 3 .

Table 3

Ballistic results of Dyneema layout from simulation and analytical model

\begin{tabular}{|c|c|c|c|c|c|}
\hline $\begin{array}{c}\text { Type of } \\
\text { projectile }\end{array}$ & $\begin{array}{l}\text { Test } \\
\text { No. }\end{array}$ & $\begin{array}{l}\text { No. of } \\
\text { Layers }\end{array}$ & $\begin{array}{c}\text { Impact } \\
\text { Velocity } \\
{[\mathrm{m} / \mathrm{s}]}\end{array}$ & $\begin{array}{l}\text { Residual Veloci- } \\
\text { ty }[\mathrm{m} / \mathrm{s}] \text { (Simula- } \\
\text { tion) }\end{array}$ & $\begin{array}{c}\text { Residual } \\
\text { Velocity } \\
\text { [m/s] } \\
\text { (Analytical) }\end{array}$ \\
\hline \multirow{4}{*}{$\begin{array}{c}7.62 \times 39 \\
\mathrm{~mm} \\
(\mathrm{AK}-47)\end{array}$} & 1 & 15 & 690 & 493 & 415 \\
\hline & 2 & 21 & 690 & 345 & 278 \\
\hline & 3 & 27 & 690 & 115 & 93 \\
\hline & 4 & 30 & 690 & $0(\mathrm{PP})$ & $0(\mathrm{NP})$ \\
\hline \multirow{4}{*}{$\begin{array}{c}7.62 \times 51 \\
\mathrm{~mm} \\
(\mathrm{G}-3)\end{array}$} & 5 & 15 & 780 & 586 & 518 \\
\hline & 6 & 21 & 780 & 442 & 385 \\
\hline & 7 & 27 & 780 & 224 & 145 \\
\hline & 8 & 30 & 780 & 55 & $0(\mathrm{PP})$ \\
\hline
\end{tabular}


As it seen in Table 3, there is a difference between the results of residual velocity of projectile in simulation and analytical model. The simulation method is more close to experimental results (Table 4). This divergence arises from completely different approaches for calculating projectile residual velocity. Fig. 5 demonstrates the penetration of 27 layered Dyneema plate by a $7.62 \times 39 \mathrm{~mm}$ projectile with the initial velocity of $690 \mathrm{~m} / \mathrm{s}$.

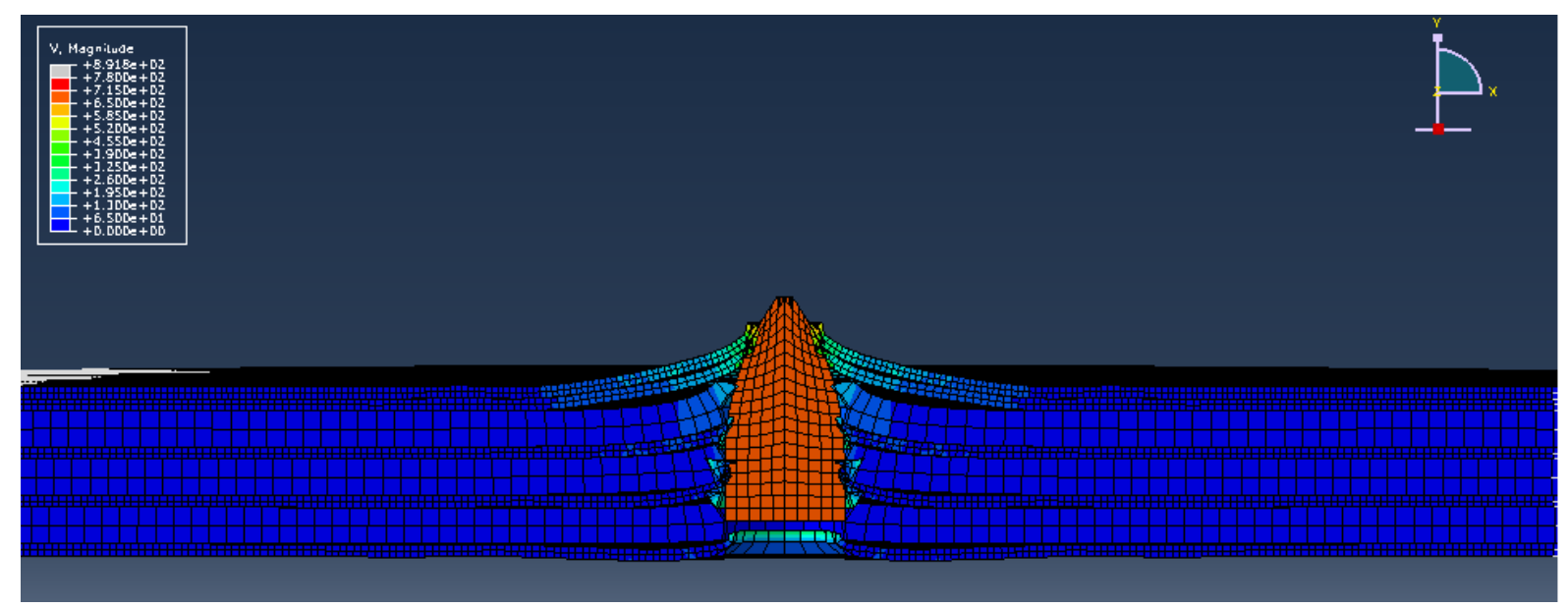

Figure 5 Complete penetration of 27 layered Dyneema plate by a $7.62 \times 39 \mathrm{~mm}$ projectile (the colors demonstrate the velocity).

Verification of simulation and analytical results by experimental tests is carried out by real ballistic test. As mentioned before, shooting tests are done according to NIJ 0101.03 standard. For each eight case, three shootings executed on the fabricated Dyneema plates. The penetration results of practical shooting tests are presented in Table 4. AK- 47 and G-3 bullet penetration in 25 layers specimen can be observed in Fig. 6 .

According to the Table 4, all of the Dyneema plates penetrated, most of them completely and some of them partially. These results are in consistency with simulation and especially with the results of analytical model. By increasing the number of Dyneema layers the probability of perforation decreases. However, it should be noted that more Dyneema layers means more average weight, which is so critical for lightweight high speed coast guard boat. Fig. 7 shows the crucial zones on the coast guard boat hull which have to be protected. 
Table 4

\begin{tabular}{ccccc}
\hline \multicolumn{4}{c}{ Ballistic results of Dyneema layout from experimental model } \\
\hline Type of Projectile & Test No. & $\begin{array}{c}\text { No. of La- } \\
\text { yers }\end{array}$ & $\begin{array}{c}\text { Trauma } \\
{[\mathbf{c m}]}\end{array}$ & $\begin{array}{c}\text { Penetration } \\
\text { Result }\end{array}$ \\
& 1 & 20 & 1.2 & $\mathrm{CP}$ \\
$\mathbf{7 . 6 2 \times 3 9 ~} \mathbf{~ m m}$ & 2 & 25 & 0.8 & $\mathrm{CP}$ \\
$(\mathbf{A K}-\mathbf{4 7})$ & 3 & 28 & 0.5 & $\mathrm{PP}$ \\
& 4 & 30 & 0.2 & $\mathrm{PP}$ \\
$\mathbf{7 . 6 2} \times \mathbf{5 1} \mathbf{m m}$ & 5 & 20 & 1.5 & $\mathrm{CP}$ \\
$(\mathbf{G}-\mathbf{3})$ & 6 & 25 & 1.1 & $\mathrm{CP}$ \\
& 7 & 28 & 0.9 & $\mathrm{CP}$ \\
\hline
\end{tabular}
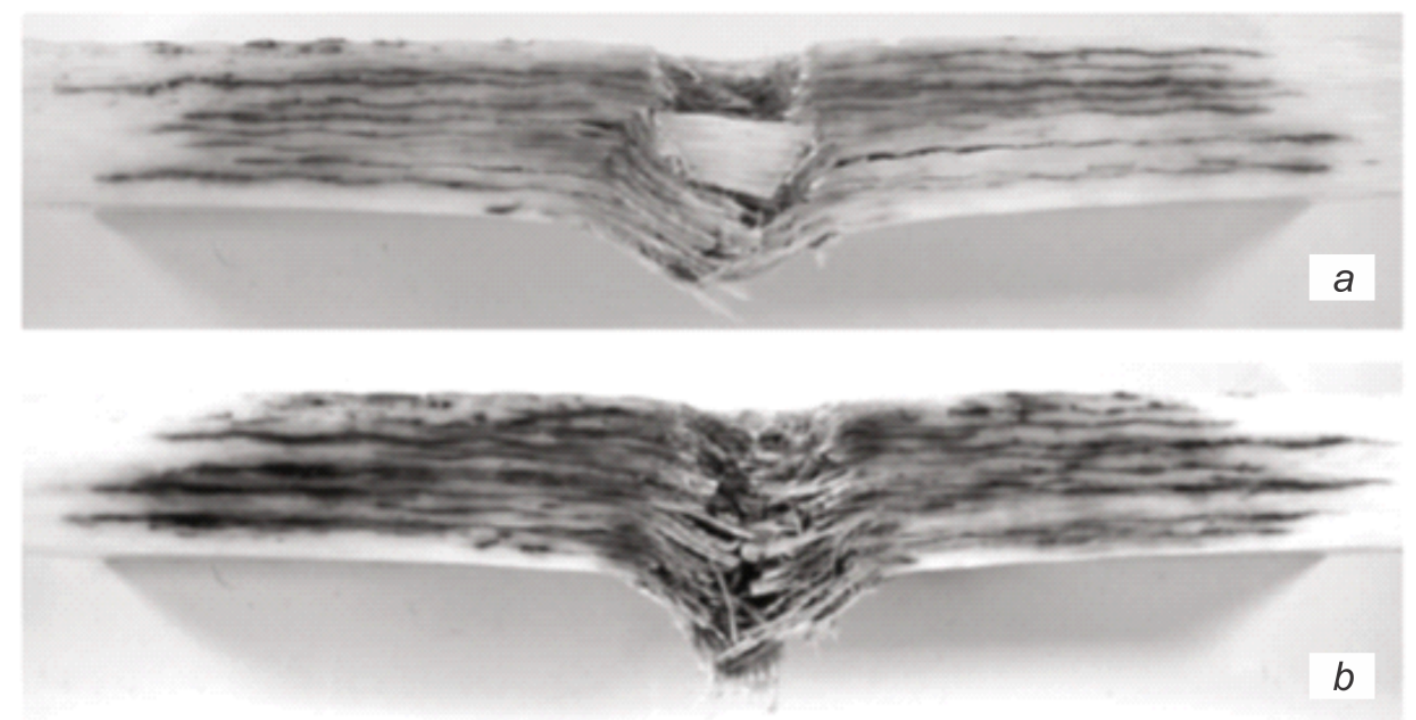

Figure 625 layers specimens after encounter: (a) AK-47 bullet (b) G-3 bullet 


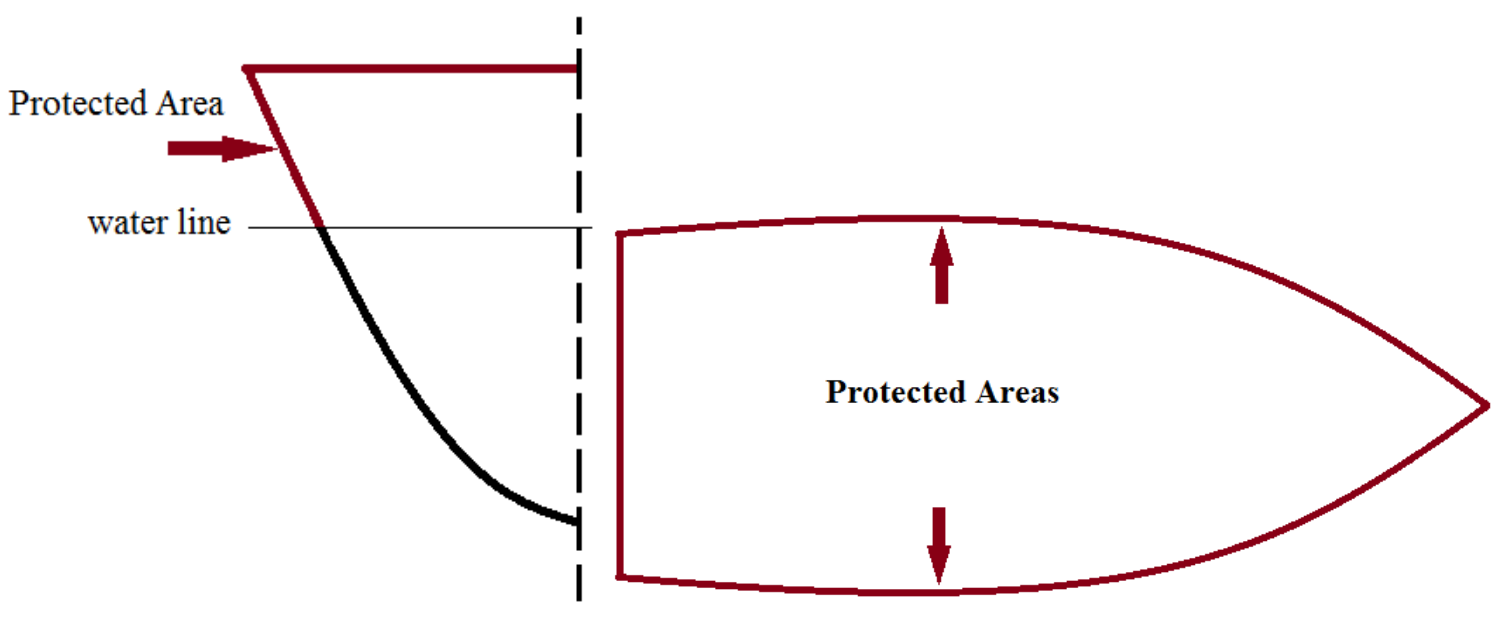

Figure 7 Protected areas which are fabricated with Dyneema composite

However, by increasing hull thickness the protection increases along with its areal weight. If length of trauma is considered as symbol of less protection; Fig. 8 shows the required thickness for having both protection and less weight of the hull fabricated from Dyneema fibers against $7.62 \times 39 \mathrm{~mm}$ projectile. The defined element which is related to the degree of fabric protection is the value of trauma (the raised part on composite's back that is caused by a bullet). The two completely penetrated $(\mathrm{CP})$ points in Fig. 8 indicate unsafe thicknesses for the hull.

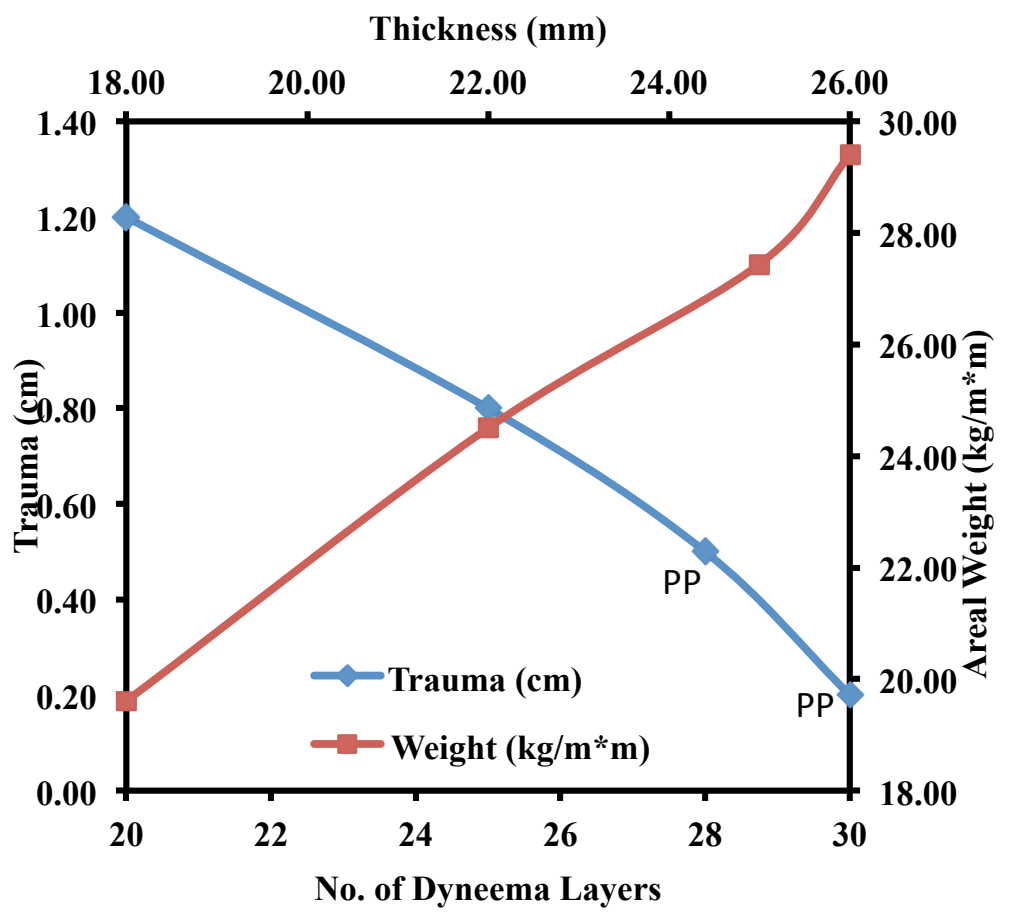

Figure 8 Thickness selection assistant curve for building coast guard boat shield resistant to $7.62 \times 39 \mathrm{~mm}$ projectile 
The same trend also derived for $7.62 \times 51 \mathrm{~mm}$ projectile which is presented in Fig. 9 .

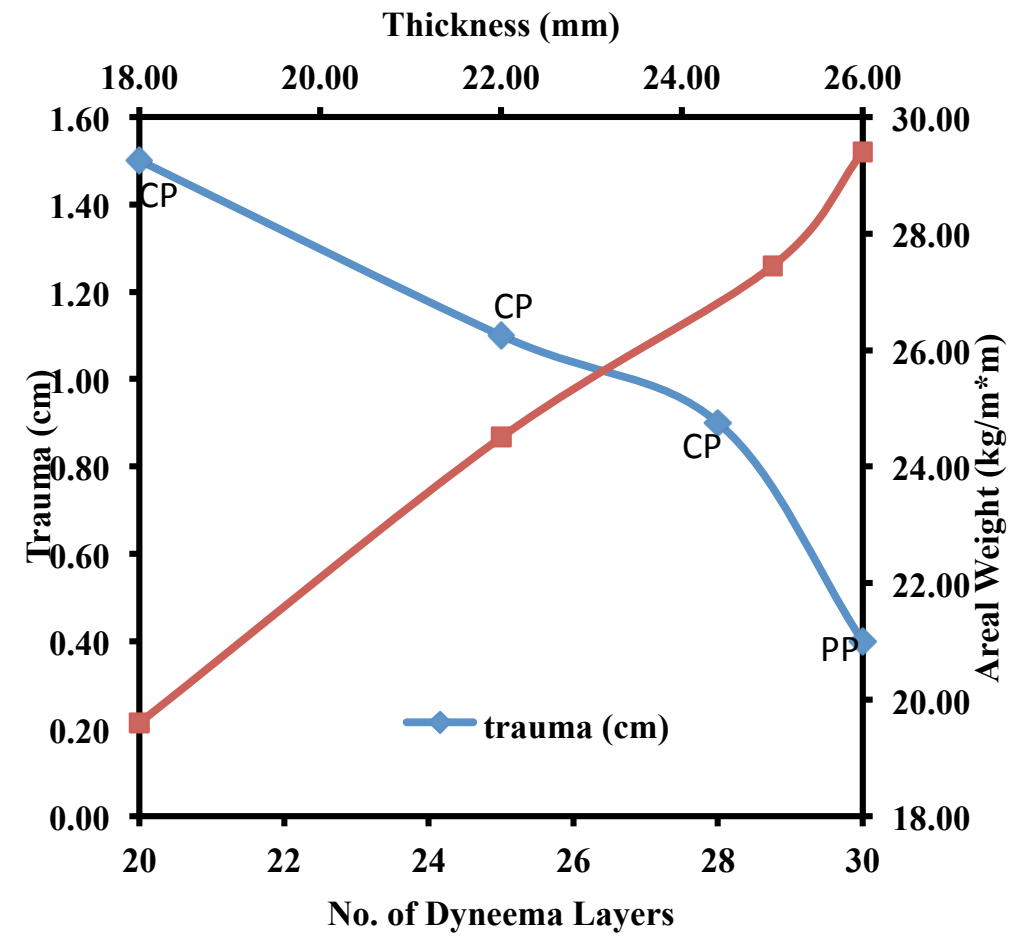

Figure 9 Thickness selection assistant curve for building coast guard boat shield resistant to $7.62 \times 51 \mathrm{~mm}$ projectile

According to Fig. 9 by increasing the projectile caliber, the protection decreases. In this condition more Dyneema layers are required to fully stop the projectile (PP). As could be observed in Fig. 8 and Fig. 9, 27 and 30 Dyneema layers are the minimum required layer to fully stop the $7.62 \times 39$ $\mathrm{mm}$ and $7.62 \times 51 \mathrm{~mm}$ projectiles respectively as stated by experiment. However, utilizing more layer costs extra weight which has an adverse effect on ship performance the designers should select the best configuration based on vessel functionality and assessment of projectile caliber, distance and risk.

In order to compare simulation and experimental results, Fig. 10 presents percent of protection relative to number of layers for AK-47 and G-3 bullets. The percentage of protection is defined as the ratio of remaining (un-penetrated) thickness to the initial (before penetration) thickness.

$$
\text { Protection } \%=\frac{t_{-} \text {remaining }}{t_{-} \text {total }} \times 100
$$

As can be observed, simulation and experimental results have good correlation but simulation results underestimate the protection level. It could be demonstrated because of idealistic model of composite layers, properties and bullet velocity. 


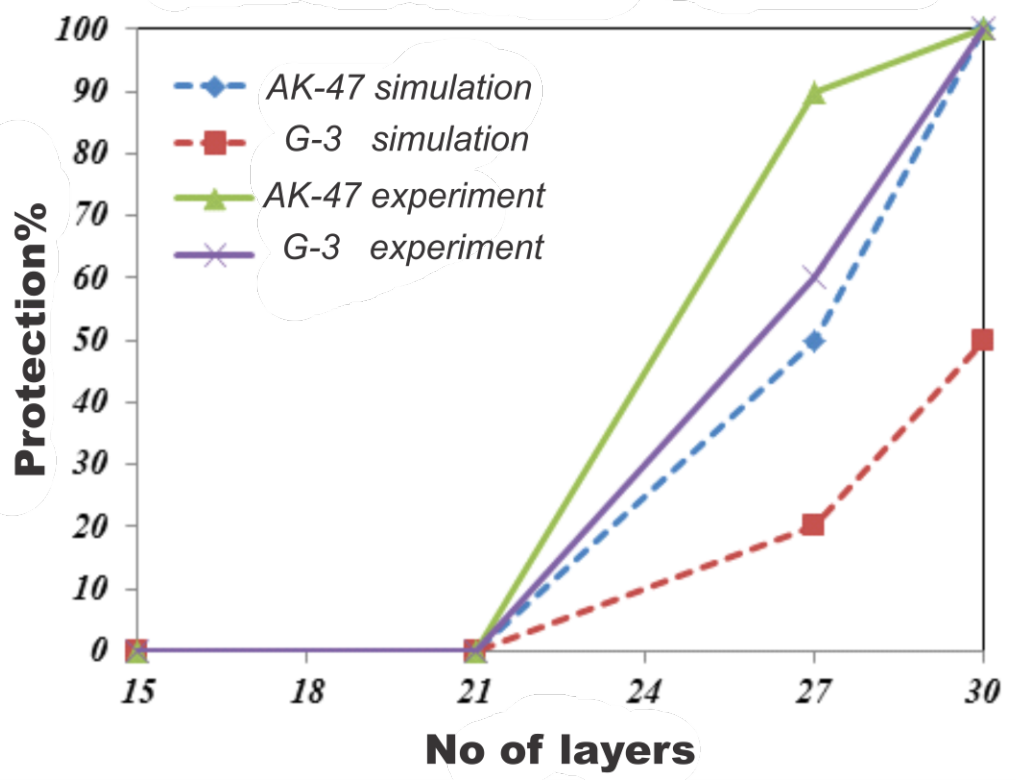

Figure 10 Percent of protection vs. number of layers for AK-47 and G-3 (simulation and experimental)

\section{RESULTS AND DISCUSSION}

The results can be summarized into the following:

1 - The analytical model developed by Chocron has been employed in order to predict the motion and projectile velocity after impact.

2 - Finite element method is utilized by ABAQUS/Explicit program. The simulation results have analogized by analytical model which revealed some discrepancies between those results.

3 - Experimental results show that at least 27 Dyneema layers are required to fully stop the $7.62 \times 39 \mathrm{~mm}$ projectile and at least 30 layers for $7.62 \times 51 \mathrm{~mm}$ projectile, however simulation results predicts 30 Dyneema layers for both projectiles and analytical results predicts 30 Dyneema layers for both projectiles.

4 - Both analytical and simulation methods (especially analytical) slightly underestimate the protection level of Dyneema fabric relative to experimental results, however, they are very useful in examining other conditions which are costly or nor practical and prediction of protection level.

5 - Dyneema fabric is a suitable choice for building coast guard boat hull, because of its easy molding and shaping, high strength and lightness.

6 - Trauma length and aerial weight for both projectiles versus number of Dyneema layers have been shown to assist designers for selection of more convenient protection shield regarding to vessel functionality and existent threats considering extra cost and ship performance.

7 - After defining a protection parameter, percent of protection relative to number of layers was shown for simulation and experimental results which can be used to demonstrate shield protection capability. 
Acknowledgment The authors acknowledge the financial support received for this work from the Iranian Research National Council and the provision of the research facilities used in this work.

\section{References}

[1] Ong, C.W., et al. (2011). Advanced layered personnel armor, International Journal of Impact Engineering 38(5): 369-383.

[2] Shokrieh, M.M. and Javadpour, G.H. (2008). Penetration analysis of a projectile in ceramic composite armor, Composite Structures 82(2): 269-276.

[3] Ernest, S.C. (1999). Army focused research team on functionally graded armor composites, Materials Science and Engineering 259(2): 155-161.

[4] Anderson J., C.E. and Bodner, S.R. (1988). Ballistic impact: The status of analytical and numerical modeling, International Journal of Impact Engineering 7(1): 9-35.

[5] Guoqi, Z., Goldsmith, W. and Dharan, C.K.H. (1992). Penetration of laminated Kevlar by projectiles - I: Experimental investigation, International Journal of Solids and Structures 29(4): 399-420.

[6] Jenq, S.T., Jing, H.S. and Chung, C. (1994). Predicting the ballistic limit for plain woven glass/epoxy composite laminate, International Journal of Impact Engineering 15(4): 451-464.

[7] Goldsmith, W., Dharan, C.K.H. and Chang H. (1995). Quasi-static and ballistic perforation of carbon fiber laminates, International Journal of Solids and Structures 32(1): 89-103.

[8] Potti, S.V. and Sun, C.T. (1997). Prediction of impact induced penetration and delamination in thick composite laminates, International Journal of Impact Engineering 19(1): 31-48.

[9] Morye, S.S., et al. (2000). Modelling of the energy absorption by polymer composites upon ballistic impact, Composites Science and Technology 60(14): 2631-2642.

[10] Billon, H.H. and Robinson, D. J. (2001). Models for the ballistic impact of fabric armour. International Journal of Impact Engineering 25(4): 411-422.

[11] Cheeseman, B.A. and Bogetti, T.A. (2003). Ballistic impact into fabric and compliant composite laminates, Composite Structures 61(1-2): 161-173.

[12] Duan, Y., et al. (2006). Finite element modeling of transverse impact on a ballistic fabric, International Journal of Mechanical Sciences 48(1): 33-43.

[13] Karahan, M., Kuş, A. and Eren, R. (2008). An investigation into ballistic performance and energy absorption capabilities of woven aramid fabrics, International Journal of Impact Engineering 35(6): 499-510.

[14] Chocron, S., et al. (2008). Lightweight polyethylene non-woven felts for ballistic impact applications: Material characterization, Composites Part B: Engineering 39(7-8): 1240-1246.

[15] Bürger, D., et al. (2012). Ballistic impact simulation of an armour-piercing projectile on hybrid ceramic/fiber reinforced composite armours, International Journal of Impact Engineering 43: 63-77.

[16] Chocron, S., Rodriguez, J. and Sánchez Gálvez, V. (1997). A Simple Analytical Model for Ballistic Impact in Composites, HAL - CCSD.

[17] Chocron Benloulo, I.S. and Sánchez-Gálvez, V. (1998). A new analytical model to simulate impact onto ceramic/composite armors, International Journal of Impact Engineering 21(6): 461-471.

[18] Smith, J.C., McCrackin, F.L. and Schiefer, H.F. (1958). Stress-Strain Relationships in Yarns Subjected to Rapid Impact Loading, Textile Research Journal 28(4): 288-302.

[19] Prosser, R.A. (1980). The Penetration of Nylon Ballistic Panels by Fragment Simulating Projectiles.

[20] Van Gorp, E.H.M., van der Loo, L.L.H. and van Dingenen, J.L.J. (1993). A model for HPPE-Based lightweight add-on armour. Ballistics, 93. 
